\title{
The Occurrence of Endopolyploid Cells During Seedling Development of Allium fistulosum $\mathbf{L}$.
}

\author{
Nobuhiro KUDO ${ }^{1 *}$, Kentaro IKEDA $^{1}$, Yasuo KIMURA $^{1}$ and Masahiro $\mathrm{MII}^{2}$ \\ 'Division of Plant Biotechnology, Gunma Agricultural Research Center, 493 Nishi-Obokata, \\ Sawa-Azuma, Gunma 379-2224, Japan \\ ${ }^{2}$ Faculty of Horticulture, Chiba University, 648 Matsudo, Chiba 271-8510, Japan \\ *Corresponding author E-mail address: kudo-n@pref.gunma.jp
}

Received 10 February 2003; accepted 1 July 2003

\begin{abstract}
The endopolyploidy during seedling development of Welsh onion (Allium fistulosum L.) is described. Flow cytometric measurements of relative nuclear DNA contents showed that certain cells became polyploid. Endopolyploidy was not present in the nuclei of embryos during imbibition. Endopolyploidization had taken place in all organs tested. Leaf segments of in vivo grown 3 month-old plants had elevated ploidy levels and contained nuclei of $2 \mathrm{C}, 4 \mathrm{C}, 8 \mathrm{C}$, and $16 \mathrm{C}$, where $\mathrm{C}$ is the haploid nuclear genome complement. The endopolyploid nuclei fall into clear ploidy series $(2 \mathrm{C}, 4 \mathrm{C}, 8 \mathrm{C}$, and $16 \mathrm{C})$. Therefore, the process of endopolyploidy appears to correspond to endoreduplication.
\end{abstract}

Key words: Allium fistulosum L., DAPI, endopolyploidy, endoreduplication, flow cytometry, Welsh onion.

\section{Abbreviations}

DAPI, 4', 6-diamidino-2-phenylindole; FCM, Flow cytometry.

Endopolyploidy (or somatic polyploidy) has been described in many eukaryotes (Nagl, 1976; Brodsky and Uryvaeva, 1977; Barlow, 1978). The occurence of endopolyploidy is very frequent in insects. A variety of cell types in Drosophila larval tissues undergo endopolyploidization (Sauer et al., 1995). In animals, endopolyploidy is observed in specific cell types such as some molluscan neurons, mammalian megakaryocytes and plancental trophoblast cells (Chase and Tolloczko, 1987; Zybina and Zybina, 1996). The occurrence of endopolyploidy is common in plants (Barlow, 1978). However, endopolyploidization events in plants are poorly understood (Trass et al., 1998). Endopolyploidy is tightly coupled to cell differentiation (Nagl, 1976). Furthermore, clear relationship was observed between endopolyploidy and cell size (Melaragno et al, 1993; Kudo and Kimura, 2002b).

Allium is a cosmopolitan genus with more than 600 species distributed in the northern hemisphere (Novák et al., 1986). They comprise major vegetable crops and many wild relatives. A. fistulosum L. (Welsh onion or Japanese bunching onion) is one of the most important horticultural crops in the genus Allium. A. fistulosum is widely cultivated from Siveria to Tropical Asia and shows morphological variability in Japan (Haishima et al., 1993). A. fistulosum is a diploid $(\mathrm{x}=8)$ biennial herbaceous plant, flowering in the second season of growth (Inden and Asahira, 1990). A. fistulosum has no well - developed bulb and shortened stem-plate from which roots and shoots arise.

The development of endopolyploidy has recently been described in economically important crops, such as Cucumis sativus (Gilissen et al., 1993), Lycopersicon esculentum (Smulders et al., 1994), several Brassica crops (Kudo and Kimura, 2001a, b), Raphanus sativus (Kudo and Kimura, 2002a) and Portulaca grandiflora (Mishiba and Mii, 2000). So far, very little information is available on the development of endopolyploidy in A. fistulosum. The objective of this study is to determine whether endopolyploidization occurs in seedling development of $A$. fistulosum.

In vitro plants of $A$. fistulosum cv. Nebuka were grown from seeds and used for the present study. Seeds were surface-sterilized for $20 \mathrm{~min}$ with $2 \%$ sodium hypochlorite solution and washed three times with sterile distilled water. Two seeds were plated on half-strength MS medium (Murashige and Skoog, 1962) containing $20 \mathrm{~g} \mathrm{l}^{-1}$ sucrose, soli- 


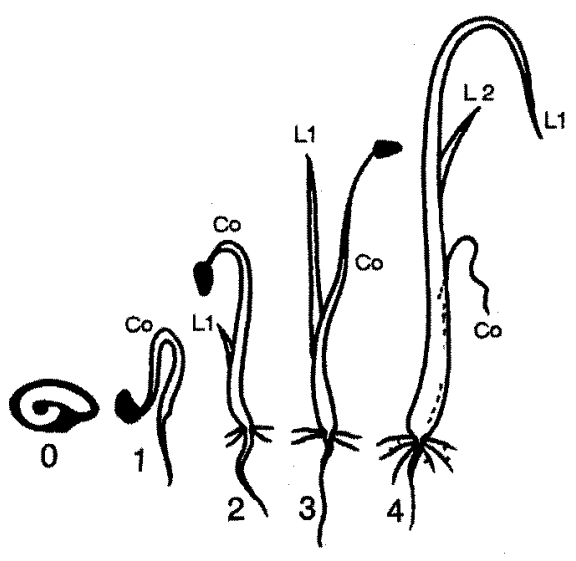

Fig. 1 Five developmental stages from seed imbibition to seedling establishment of Allium fistulosum cv. Nebuka under in vitro conditions. Stage 0: embryo 4 h after imbibition with no sign for germination; Stage 1: 1 day-old seedling, outgrowth of the radicle and upward elongation of the cotyledon; Stage 2: 10 day-old seedling, appearance of the first leaf; Stage 3: 20 day-old seedling, development of the first leaf; Stage 4: 30 day-old plant, development of the second leaf, expansion of the first leaf, and wilting of the cotyledon.

Co $=$ cotyledon, $L 1=$ the first leaf, and L2 = the second leaf.

dified with $2.5 \mathrm{~g} \mathrm{l}^{-1}$ Gelrite in a $500-\mathrm{ml}$ glass jar; $\mathrm{pH}$ of the medium was adjusted to 5.8 before autoclaving at $121^{\circ} \mathrm{C}$ for $20 \mathrm{~min}$. Plants were grown at $25^{\circ} \mathrm{C}$ under cool white fluorescent lights (50 $\mu \mathrm{mol} \mathrm{m}^{-2} \mathrm{~s}^{-1}$ ) with a $16^{-\mathrm{h}}$ day light/8-h dark photoperiod. Seeds were also sown in soil and in vivo plants were cultivated in a greenhouse. Leaf segments were harvested after three months of culture.

DNA content of nuclei from embryos and plants at different developmental stages was determined by flow cytometry (FCM). The developmental stages of in vitro plants are classified into five categories according to their morphology distinguished from embryos to 30 day-old plants (Fig. 1). Nuclei were extracted and stained with 4, 6-diamidino-2-phenylindole (DAPI) using a high resolution kit (PARTEC High Resolution Kit type P, Partec GmbH, Münster, Germany).

For the FCM analysis on in vitro plants, tissue samples were harvested from four embryos which were carefully excised from seeds after $4 \mathrm{~h}$ of culture (stage 0), and from seedlings at different developmental stages (stage 1-stage 4) by dissecting into several parts, i. e., leaves, cotyledon, and roots. The leaves were numbered from bottom to top, with the oldest leaf as number one.

For in vivo plants, the segments $\left(1.0 \mathrm{~cm}^{2}\right)$ of central portion of the outer leaf were harvested and used for the analysis.

The samples were chopped with a razor blade in a few drops of nuclei extraction buffer (solution $A$ of the kit). A 1-2 ml of staining solution containing DAPI (solution B of the kit) was added and the sample was passed through a $100-\mu \mathrm{m}$ Cell Trics filter (PARTEC). Fluorescent microscopic observations confirmed that isolated nuclei were not clumping. The analyses were performed with a PAS flow cytometer (PARTEC) equipped with an HBO 100 mercury arc lamp. The signals of nuclei within each peak were determined by Flow Max software (PARTEC). Mean and coefficient of variation of fluorescence peaks were estimated with WinMDI software (version 2.8, copyright (C) 93-99 Joseph Trotter). In analysis of each sample, a minimum of 3,000 nuclei were totally counted at a rate of $10-20$ nuclei $\mathrm{s}^{-1}$. Measurements of nuclear DNA content were carried out with at least 6 replications. To determine the position of $2 \mathrm{C}$ peak, nuclei of in vitro young leaves were analyzed twice on each measurement. The data were plotted on a semi-logarithmic scale, so that the histograms from $2 \mathrm{C}$ to $16 \mathrm{C}$ were evenly distributed along the abscissa. The data were presented as percentage of the total amount of nuclei in all peaks of the histogram.

In vivo plants were harvested after three months of culture and the abaxial epidermis of the most outer leaves was used for the microscopic obeservation of nuclei. The peeled epidermis was placed on a glass slide and immersed in a drop of DAPI at a concentration of $5 \mu \mathrm{g} \mathrm{ml}^{-1}$ for $5 \mathrm{~min}$. The epidermis was then washed in distilled water and observed under epifluorescence microscopy (model BHSRFC, Olympus) using the $\times 20$ objectives of a microscope.

In most cases, FCM histograms were sharp, and coefficients of variation (CV\%) lay between 1.3 and 4.9. Because $A$. fistulosum is a diploid species, $2 \mathrm{C}$ DNA level corresponds to the diploid state of the genome found in the $\mathrm{G} 1$ phase, while 4C DNA level coincides with $\mathrm{G} 2$ phase of dipolid which results from the $S$ phase duplication of chromatids, and thus, an indicator of the capacity of cells to enter mitosis. However, the $4 \mathrm{C}$ value may not be the $\mathrm{G}_{2}$ state of diploid, but may represent an endopolyploid form of the genome. In this case, the presence of $8 \mathrm{C}$ nuclei is an indicator of the capacity of cells to enter endopolyploidization events.

FCM histograms from embryonic nuclei at stage 0 showed a large $2 \mathrm{C}$ peak $(85 \%$ of total nuclei counted) and a second smaller peak (15\%) with twice the amount of fluorescence, corresponding to nuclei with replicated 4C DNA content (Fig. 2A). 

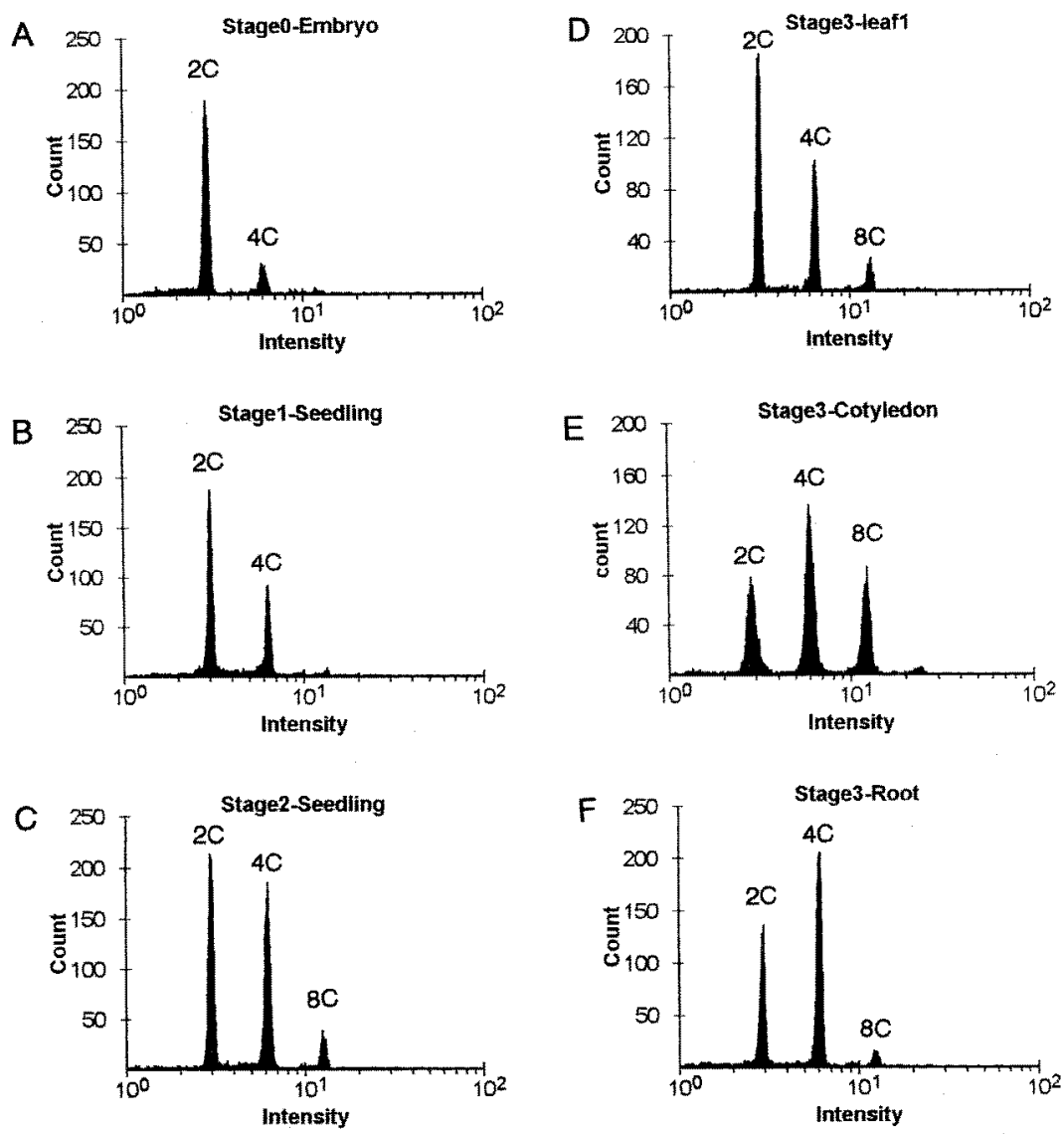

Fig. 2 Characteristic histograms of nuclei distribution from Stage 0 to Stage 3. of Allium fistulosum cv. Nebuka. (A) Embryo at Stage 0, (B) Whole seedling at Stage 1, (C) Whole seedling at Stage 2, (D) Leaf1 at Stage 3, (E) Cotyledon at Stage 3, (F) Root at Stage3.
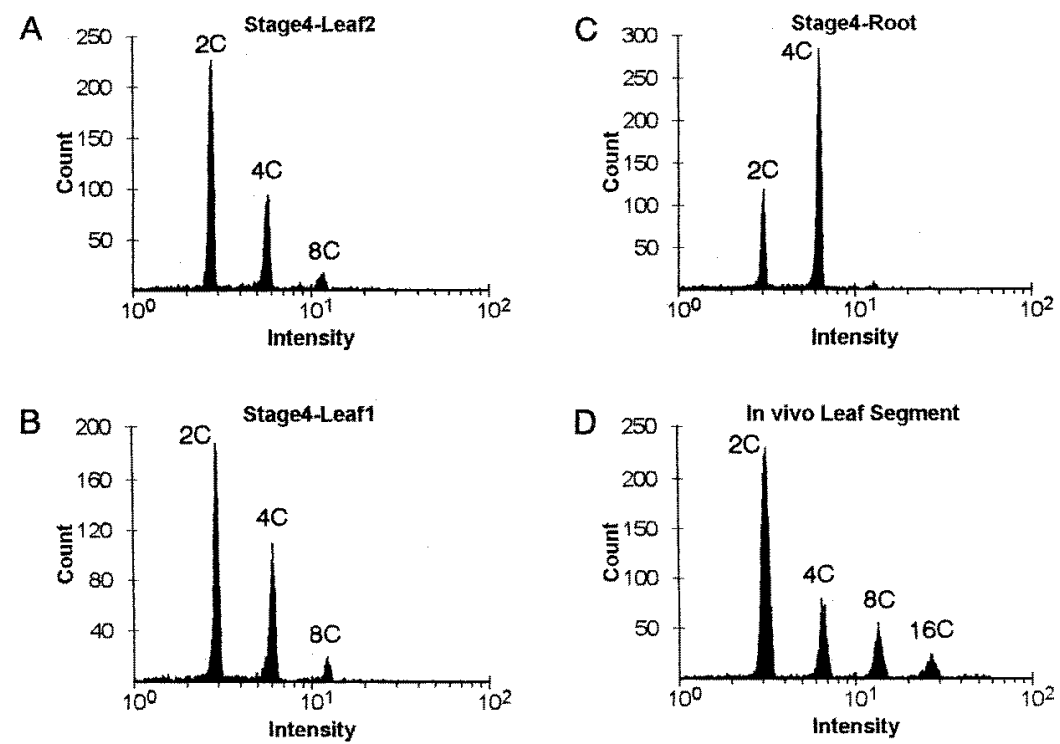

Fig. 3 Characteristic histograms of nuclei distribution from organs of in vitro plants at Stage 4 and leaf segments of in vivo plants of Allium fistulosum cv. Nebuka. (A) Leaf 2 at Stage 4, (B) Leaf 1 at Stage 4, (C) Root at Stage 4, (D) Leaf segment of in vivo plants.

During imbibition, the elevated water content of the seeds may trigger the initiation of cell cycle events. Germinating seedlings at stage 1 had increased the frequency of $4 \mathrm{C}$ nuclei (Fig. $2 \mathrm{~B}$ ). $25 \%$ of somatic cells in the seedlings had already $4 \mathrm{C}$ nuclei. The first cycle of endopolyploidization of nuclear DNA had taken place at stage 2 as indicated by the appearance of a small population of $8 \mathrm{C}$ nuclei (Fig. 2C). The whole seedlings at this stage contained about $10 \%$ of $8 \mathrm{C}$ cells. At stage 3 , endopolyploidy was observed in the somatic cells of all organs tested (Fig. 2D-F). The percentage of nuclei with 


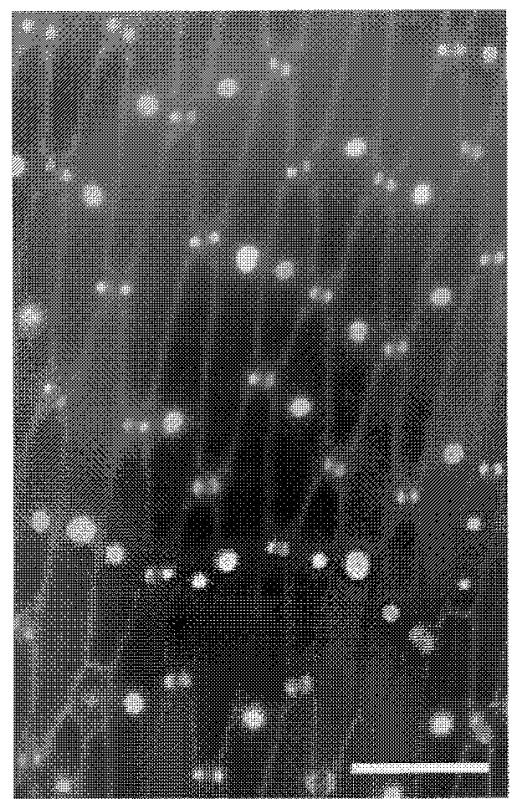

Fig. 4 Fluorescence of DAPI-stained nuclei in the abaxial epidermis of the outer leaf of in vivo plants in Allium fistulosum cv. Nebuka. Bar = $100 \mu \mathrm{m}$.

$8 \mathrm{C}$ level varied from $4 \%$ to $25 \%$ of the total nuclei comnted among the organs. Cotyledon had $25 \%$ of 8C nuclei (Fig. 2E) and leaf 1 had $8 \%$ (Fig. 2D) while root had only $4 \% 8 \mathrm{C}$ (Fig. 2F). At stage 4, multiploidy was detected in leaf 1 and leaf 2 (Fig. $3 \mathbf{A}, \mathbf{B})$. Leaf 1 and leaf 2 contained $10 \%$ and $7 \%$ of endopolyploid nuclei ( $8 \mathrm{C}$ ), respecitvely. In leaf 1 , the frequency of $8 \mathrm{C}$ cells slightly increased. In contrast to the endopolyploid organs, root tissues reduced their ploidy level and had virtually only diploid (2C-4C) nuclei (Fig. 3C).

Endopolyploidy was also detected in leaf seg ments of in vivo plants. The third round of endopolyploidization (16C) was observed (Fig. 3D).

The observation of DAPI-stained epidermal tissues revealed apparent differences in nucleus size in relation to cell size (Fig. 4). Guard cells had small nuclei whereas large elongated epidermal cells had large nuclei.

In the present study, A. fistulosum is revealed to be a species with endopolyploidy up to $16 \mathrm{C}$. The endopolyploid nuclei fall into clear ploidy series $(2 \mathrm{C}, 4 \mathrm{C}, 8 \mathrm{C}$, and $16 \mathrm{C})$. Therefore, the process of endopolyploidy appears to correspond to endoreduplication. Since the cells with $8 \mathrm{C}$ content are not found in the germinationg embryo but appear with the initiation of first leaf, it might be possible that endopolyploidization begins with some cells of cotyledon and leaves. A similar change in the pattern of endopolyploidy has been observed previously in other plant species such as Cucumis sativus (Gilissen et al., 1993), and Brassica oleracea (Kudo and Kimura, 2001b). Therefore, the development of endopolyploidy during the early stage of germination might be a common feature in a wide range of plant species. Because a strong correlation was found between cell size and nuclear size in leaf epidermal cells of $A$. fistulosum (Fig. 4), endopolyploidy of this species might be associated with cell differentiation as described previously (Kondorosi et al., 2000; Kudo and Kimura, 2002b). Although the physiological role of endopolypolidy in A. fistulosum is still unclear, it is possible that gene expression might be increased in these endopolyploid cells with increase in the available DNA templates (Nagl, 1976; Baluška and Kubica, 1992; Larkins et al., 2001). Further studies are required to clarify the physiological role of the endopolyploidization in this important crop.

\section{References}

Baluška, F., Kubica, S., 1992. Relationships between the content of basic nuclear proteins, chromatin structure, rDNA transcription and cell size in different tissues of the maize root apex. J. Exp. Bot., 43: 991 - 996.

Barlow, P. W., 1978. Endopolyploídy: towards an undetstanding of its biological significance. Acta Biotheor, 27: 1-18.

Brodsky, W. Y. Uryvaeva, I. V., 1977. Cell polyploidy: its relation to tissue growth and function. Int. Rev. Cytol, 50: $275-332$.

Chase, R., Tolloczko, B., 1987. Evidence for differential DNA endoreduplication during the development of a molluscan brain. J. Neurobiol., 18: 395-406.

Gilissen, L. J. W., Van Staveren, M. J., Creemers-Molenaar, J., Verhoeven, H. A., 1993, development of polysomaty in seedlings and plants of Cucumis sativus L. Plant Sci., 91: 171-179.

Haishima, M., Kato, J., Ikehashi, H., 1993. Isozyme polymorphism in native varieties of Japanese bunching onion, Allium fistulosum L. Jpn. J. Breed., 42: 497-505.

Inden, H., Asahira, T., 1990. Japanese bunching onion Allium fistulosum L. In: Brewster, J. L., Rabinowich, H. D. (Eds.); Onion and allied crops, Vol. 3, pp. 159-178. CRC Press, Boca Raton.

Kondorosi, E., Roudier, F., Gendreau, E., 2000. Plant cellsize control: growing by ploidy? Curr. Opin. Plant Biol., 3: 488-492.

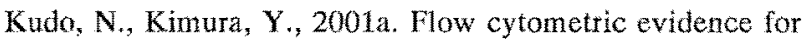
endopolyploidy in seedlings of so me Brassica species. Theor. Appl. Genet, 102: 104-110.

Kudo, N., Kimura, Y., 2001b. Patterns of endopolyploidy during seedling development in cabbage (Brassica oleracea L.). Ann. Bot, 87: 275-281.

Kudo, N., Kimura, Y., 2002a. Flow cytometric analysis for systemic endopolyploidy in development of radish (Raphants sativas L.). Plant Biol., 19:45-52.

Kudo, N,; Kimura, Y., 2002b. Nuclear DNA endoreduplication during petal development in cabbage: rela. tionship between ploidy levels and cell size. J. Exp. Bot., 53: 1017-1023. 
Larkins, B. A., Dilkes, B. P., Dante, R. A., Coelho, C. M., Woo, Y.- M., Liu, Y., 2001. Investigating the hows and whys of DNA endoreduplication. J. Exp. Bot, 52: 183192.

Melaragno, J. E., Mehrotra, B., Coleman, A. W., 1993. Relationship between endopolyploidy and cell size in epidermal tissue of Arabidopsis. Plant Cell, 5: 16611668.

Mishiba, K., Mii, M., 2000. Polysomaty analysis in diploid and tetraploid Portulaca grandiflora. Plant Sci., 156: $213-219$

Murashige, T., Skoog, F., 1962. A revised medium for rapid growth and bioassays with tobacco tissue culture. Physiol. Plant, 15: 473-493.

Nagl, W., 1976. DNA endoreduplication and polyteny understood as evolutionary strategies. Nature, 261: 614 $-615$.

Novák, F, J., Havel, L., Dolezel, J., 1986., Allium. In:
Evans, D. A. et al. (Eds.): Handbook of Plant Cell Culture, Vol.4., pp. 419-456. Macmillan, New York.

Sauer, K., Knoblich, J. A., Richardson, H., Lehner, C. F., 1995. Distinct modes of cyclin $\mathrm{E} / \mathrm{cdc} 2 \mathrm{c}$ kinase regulation and $\mathrm{S}$-phase control in mitotic and endoreduplication cycles of Drosophila embryogenesis. Gene. Dev., 9: 1327-39.

Smulders, M. J. M., Rus-Kortekaas, W., Gilissen, L. J. M., 1994. Development of polysomaty during differentiation in diploid and tetraploid tomato (Lycopersicon esculentum) plants. Plant Sci., 97: 53-60.

Trass, J., Hülskamp, M., Gendreau, E., Höfte, H. 1998. Endoreduplication and development: rule without dividing? Curr. Opin. Plant Biol., 1: 498-503.

Zybina, E. V., Zybina, T. G., 1996. Polytene chromosomes in mammalian cells. Int. Rev. Cytol., 165: 53-119. 